the disease. On the 23rd I began the lactic acid treatment, gradually increasing the strength of the acid from 10 per cent. to 60 per cent. Finding little benefit derived from its use, I later employed a paint of 20 per cent. menthol in olive oil. After five months the local condition showed little improvement, although by careful dieting the patient had improved in weight and general health. 'Two medical men saw the case in consultation with me and neither felt any doubt as to its tuberculous nature. One, an experienced bacteriologist, found numerous bacilli in a microscopical specimen of the secretion. On March 7th, 1891, I applied a drop of saturated solution of papain in glycerine with a laryngeal probe to the anterior extremity of the ulcerated cord. A few hours later I found a clean depression at the spot, free from the dirty-grey secretion that covered the rest of the cord. After this I applied papain freely each day by insufflation of the powder or by painting with a glycerine solution. The cord very soon presented a healthy, smooth appearance and showed signs of healing from the anterior extremity. By April 20th the cord had apparently healed and regained its natural colour, except for a pinkish tinge over its middle third. The patient was then obliged to leave the neighbourhood, and I did not see him again until May 25th, when the ulceration was healed, except at one spot. The papain was continued, and by June 22nd it was hard to tell which had been the diseased cord. I examined the larynx at intervals after that, and last saw it on Jan. 3rd, 1892, when I made the following note "Left cord slightly thicker than right; surface quite normal some swelling in arytenoid commissure; cough almost gone. Weight 10 st. $5 \frac{1}{2} \mathrm{lb}$. (weight on Jan. 5th, 1891, was 10 st. $1 \frac{1}{2} \mathrm{lb}$.)." I have received a report from the patient dated April 25th, 1893, in which he gives a very bad account of the progress of the disease in his lungs, but states that his larynx shows no signs of disease.

3. Lupus. - Six months ago I was consulted by a man suffering from lupus vulgaris. He had a patch about the size of a two-shilling piece on the left cheek, extending from the ala of the nose. From the history of the case and its appearance I felt there could be no doubt as to the diagnosis, but in order to make the test more reliable I had the diagnosis confirmed by the opinion of two other medical men. I gave the patient a saturated solution of papain in glycerine, with instructions that a small quantity was to be rubbed in over the patch night and morning. The patient did not carry out my instructions regularly; but in two months there was a great improvement in its appearance. The papules had disappeared, and although the surface was still raw and red it had a healthier appearance and showed marked signs of general healing. At the present time the ulceration has completely healed, the surface being soft and flexible and only slightly discoloured. Mr. Lightoller has quoted a case to me of lupus vulgaris which on two occasions he had extensively scraped and cauterised. As the ulceration recurred, he employed papain, under which the disease apparently dis. appeared, and after a lapse of three years there has been no retarn.

I know that single cases prove little or nothing ; but these, I consider, warrant a further trial being given to papain, the usefulness of which may possibly be greatly extended.

Barcaldine, Queensland.

\section{RETENTION OF A COIN IN THE ALIMENTARY} CANAL FOR MORE THAN NINE MONTHS.

\section{By James Kearney, M.R.C.S. ENG.}

I VenTURe to send this case to THE LANCET, deeming it worthy of publication.

About ten months ago I was called to see a child aged one year and seven months who had swallowed a foreign copper coin slightly larger than a farthing. On my arrival there was nothing in the appearance of the child to indicate anything unusual having occurred. I recommended the mother to feed the child on boiled bread and porridge for the next two days and to watch for the passage of the coin by the bowels. I visited the child on the following two days and was informed that the coin had not passed. I did not see the child again for four months, when I was called to attend it for bronchitis, and was told that the coin had not passed in the interval. was inclined to conclude either that the coin had been passed without being noticed or that the child had not really swallowed it, but the parents still persisted in saying that the coin was in the "bowels." A few days ago to my surprise I was told by the father that the child had passed the coin, it having been retained in the alimentary tract for nine months and four days. I may say that the child had no convulsions and did not scem to be injuriously affecter in any way by the retention.

Dr. Edward Browne, physician to St. Bartholomew's Hospital, records in his description of Vienna (Travels, 1685) a case in which a knife swallowed by a Bohemian peasant remained in the stomach for nine months; and Danicl l3ecker, in his " De Cultrivoro Prussiaco Observatio et Curatio," pubished in 1638, described a sinilar case. Many instances of the retention of coins and other articles in the alimentary canal are recorded in museum catalog ues and medical journals ; but every example which illustrates the fact that immediate operative interlerence is unnecessary and that too energetic medical treatment need not be adopted has some value.

Bartholomew.close, E.C.

\section{LIGATURE OF THE EXTERNAL ILIAC ARTERY FOR} ANEURYSM OF THE POPLITEAL AND FEMORAL ARTERIES OCCURRING IN THE RIGHT LIMB.

By F. EnsoR, M.R.C.S. \&c.

THE patient was a stoutly built man aged twenty-seven with dark eyes and hair, pale complexion and stains on the legs and back suggestive of syphilis, the acquisition of which was denied; he was of active habits. He stated that about the beginning of February, 1891, in the act of running he slipped on the wet grass and fell, and at once felt a pain at the back of his right knee. He took no further notice of the accident until in September he noticed a swelling at the back of the joint which was painful and pulsated. He then went to a medical man, who gave him medicine and applied pressure over the artery in the thigh nearly every day for two months. Shortly after going to the medical man he noticed a swelling in the groin which pulsated. He was admitted into the Provincial Hospital, Port Elizabeth, on Dec. 15th, 1891. The appearance of the limb on this date was as follows: The leg was slightly bent on the thigh and the muscles were wasted, and a feebly pulsating tumour as large as a medium-sized cocoa-nut occupied the popliteal space and extended up the limb; there were stains of pressure in the line of the femoral artery on the skin. Another tumour about the size of a large egg, which caused much pain and pulsated strongly, occupied the site of the common femcral artery. The diagnosis was easy. Accordingly, on Dec. 23rd I put a carbolised silk ligature on the external iliac artery, cutting both ends short. I used a drainage-tube and dressed with iodoform. The subsequent treatment offers nothing of moment to record. The pulsation stopped in both aneurysms. The foot, wrapped in wadding and flannel, retained its temperature and no bad symptoms supervened. He was allowed to return to his home, a few miles out of town, a little over a month after the operation. A few days before leaving he was given the following medicine: six drachms of syrup of iodide of iron, three drachms of solution of bichloride of mercury, one drachm of dilute nitric acid-water to twelve ounces; one ounce to be taken three times a day, which he continued to take, with intervals of a week or ten days, with the greatest benefit, as evidenced by the nearly total disappearance of the stains on the skin, and he is now in a condition of robust health.

Now I would crave space for a few lines about the operation itself and ask a question concerning the landmarks of the operation for ligature of the external iliac artery, an operation which I apprehend occurs but seldom, even in the practice of the busiest surgeon, and one which any surgeon must approach with a keen sense of responsibility. I may state that I ligatured the external iliac on dead subjects three times a few days before operating; twice with success, and once I failed by reason of opening the peritoneum and the consequent escape of intestine. I roticed that it seemed easier to avoid wounding the peritoneum during operation on the living tissue than on the dead because of the elastic resistance of the former. Although I may seem to be tedious to any anatomical demonstrator who may read these lines, yet I think they will be of use to any young surgeon who has to operate on the artery in question. Before the operation of course I had made up my mind as to the length and course of the incision, which I intended to be as follows: To strike a line from the umbilicus to the 